\title{
Application of a drive and an associative theory to the effects of CR-contingent increments and decrements in unconditioned stimulus intensity
}

\author{
WILLIAM F. PROKASY \\ University of Utah, Salt Lake City, Utah 84112
}

\begin{abstract}
An analysis of data from classical aversive conditioning of the nictitating membrane of rabbits with the two-phase model was made in order to test predictions from Spence's drive theory and the Rescorla-Wagner associative theory. While overall group means were ordered as expected from these theories, the interrelationships among estimates of parameters in the two-phase model showed that neither can account for more detailed analyses of the data. It was shown, for example, that the inferior performance of subjects receiving an avoidance treatment was not, as theoretically predicted, a result of the CR-contingent omission of the US leading to a decrement in response probability. Similarly, it was shown that increments in response probability followed trials on which the CR occurred even when CR-contingent US intensity was lower than that on non-CR trials, an effect which neither theory can predict since both are response independent. These two outcomes are opposite to what has been obtained in human aversive conditioning, which means that the two theories, while accounting for the behavior of one species, are of limited generality across species.
\end{abstract}

In an effort to examine the implications of the law of effect for aversive conditioning, Coleman (1975), with rabbit subjects, made US (unconditioned stimulus) intensity contingent on whether or not a CR (conditioned response) occurred. Thus, given a specific US intensity on $\overline{\mathrm{CR}}$ (non-CR) trials, different groups received an increment, no change, a decrement, or the omission of a US when a CR occurred. The general outcome was that as response-contingent US intensity increased, CR (a nictitating membrane response) probability increased. As observed by Coleman (1975) and Gormezano and Coleman (1973), this result is contrary to what would be expected from theories which incorporate some version of the law of effect (e.g., Hebb, 1956; Perkins, 1968; Schlosberg, 1937), but is consistent with what would be expected from a drive theory (Spence, 1956, 1960).

Clark and Prokasy (in press) replicated with human subjects the results obtained by Coleman (1975). By employing the two-phase model (Prokasy, 1972; Prokasy \& Harsanyi, 1968), these investigators also were able to determine the extent to which drive theory accounts for the fine-grain structure of the data. The analysis uncovered response-dependent contingencies, some of which were consistent with the theory and some of which were not. These are best understood by examining the model. During Phase 1 , a subject responds at a constant rate $\left(\mathrm{P}_{\mathrm{o}}\right)$, and during Phase 2, either increments or decrements in response probability can occur depending upon the outcome of the previous trial. $P_{i}$, response pro-

This research was supported by NSF Grant BMS-10471 to William F. Prokasy and by NSF Grant GB-41531 to Isadore Gormezano. bability on trial $i$, is expressed as:

(1) $P_{i}=P_{0}, i=1, K$;

(2) $\mathrm{P}_{\mathrm{i}}=\mathrm{P}_{\mathrm{i}-1}+\theta_{1}\left(\lambda_{1}-\mathrm{P}_{\mathrm{i}-1}\right), \mathrm{i}>\mathrm{K}$, given $\mathrm{CR}$ on trial $\mathrm{i}-1$;

(3) $\mathrm{P}_{\mathrm{i}}=\mathrm{P}_{\mathrm{i}-1}+\theta_{2}\left(\lambda_{2}-\mathrm{P}_{\mathrm{i}-1}\right), \mathrm{i}>\mathrm{K}$, given $\overline{\mathrm{CR}}$ on trial $\mathrm{i}-1$;

where $K+1$ is the trial on which a subject enters Phase 2, $\theta_{1}$ and $\theta_{2}$ are rate parameters, and $\lambda_{1}$ and $\lambda_{2}$ are operator limits. Note that, during Phase 2, one operator applies to $\mathrm{CR}$ trials and the other to $\overline{\mathrm{CR}}$ trials. Parameters are estimated separately for each subject.

Clark and Prokasy (in press) obtained, consistent with the theory, three outcomes. First, for most subjects, $\lambda_{1}=\lambda_{2}$ and increased with average US intensity. Second, since inhibition is generated on trials on which a US does not occur, $\lambda_{1}$ should be less than $\lambda_{2}$ in an avoidance preparation, a result that was obtained for most subjects who both received the avoidance treatment and also had $\lambda_{1} \neq \lambda_{2}$. Third, for those subjects requiring two operators, the higher limit was generally associated with the higher US intensity, regardless of whether it was on a CR or a $\overline{C R}$ trial. This last result is consistent with the theory if it is assumed that either habit strength or drive can decrease on a trial-by-trial basis within a session in which multiple USs are employed.

Outcomes not consistent with the Spence drive theory are also several-fold. First, some subjects in a conventional classical conditioning group required two operators to account for their data. Since the theory is 
response independent, such a result is unexpected. Second, that a single limit was sufficient for most subjects in the avoidance treatment causes some difficulty, although in the absence of a theoretical inhibition function the extent of the difficulty is unknown. Third, fewer subjects required two operators with a CR decrement than with the standard classical treatment, a puzzling result in view of the fact that differential operations existed in the former.

The purpose of the present paper is to employ the two-phase model to examine in greater detail the Coleman (1975) data. ${ }^{1}$ From the Spence theory, the following predictions can be made: as average US intensity increases, the common operator limit should increase; for subjects in which two operator limits are required, the greater limit should be associated with the greater US intensity; subjects receiving a classical conditioning preparation should require but a single operator in Phase 2 ; and, as a special case, $\lambda_{1}$ should be less than $\lambda_{2}$ for subjects in an avoidance preparation.

Phase 2 of the model can also be seen as a representation of the Rescorla-Wagner (Rescorla \& Wagner, 1972) theory, and several predictions can be made for the Coleman data. First, if subjects differentiate US intensities on $\mathrm{CR}$ and $\overline{\mathrm{CR}}$ trials, both the rate and limit of the operator applying on the trial with the lower US intensity should be less than their counterparts for the higher US-intensity trial. Second, a single operator should be required during Phase 2 for subjects in a classical conditioning treatment, since the theory is responseindependent. Third, subjects receiving avoidance training should yield $\lambda_{1}<\lambda_{2}$, with $\lambda_{1}$ being approximately equal to $P_{\mathbf{o}}$.

\section{METHOD}

\section{Experiment 1}

Subjects. The subjects were 84 naive male and female albino rabbits, 80-100 days old.

Apparatus. The conditioning chambers and transducer for recording the nictitating membrane response have been described by Coleman and Gormezano (1971). The CS was a 92-dB (A) $1,000-\mathrm{Hz}$ tone, $500-\mathrm{msec}$ in duration, which was superimposed on a $75-\mathrm{dB}$ white-noise background. The standard US was a $100-\mathrm{msec}, 5.0-\mathrm{mA}, 60-\mathrm{Hz}$ shock delivered to the paraorbital region through two stainless steel Autoclip sutures applied 10 $\mathrm{mm}$ apart and $10 \mathrm{~mm}$ posterior to the dorsal canthus of the right eye. The CR-contingent USs were equivalent to the standard US in all characteristics but amperage. The CS-US interval was 400 msec, and a comparator circuit was adjusted so that a membrane extension of $0.5 \mathrm{~mm}$ or more (i.e., the CR criterion) activated the comparator. The comparator output operated mercury relays to determine the UCS intensity for that subject: CR-contingent intensity value appropriate to that subject's condition if a CR was made, or the standard 5.0-mA UCS if no CR was made. The comparator revealed detection rates of $99.90 \%$ and $99.97 \%$ and false alarm rates of $.10 \%$ and $.05 \%$ for Experiments 1 and 2, respectively.

Procedure. All subjects received 1 day of preparation, a 2-day recovery period, one session of habituation to the conditioning chamber, and 6 days of acquisition training. On the preparation day, a 2-mm-diam loop of 00 Ethicon monofilament nylon was
Table 1

Number of Subjects in Each Group for Whom Particular Relationships Among Parameters are Appropriate

\begin{tabular}{ccccc}
\hline & \multicolumn{5}{c}{ Parameter Categories } \\
\cline { 2 - 5 } Group & $\begin{array}{l}\theta_{1}=\theta_{2} \\
\lambda_{1}=\lambda_{2}\end{array}$ & $\begin{array}{l}\theta_{1} \neq \theta_{2} \\
\lambda_{1}=\lambda_{2}\end{array}$ & $\theta_{1}=\theta_{2}$ & $\lambda_{1} \neq \lambda_{2}$ \\
\hline $5-0$ & 14 & 0 & $\lambda_{1} \neq \lambda_{2}$ \\
\hline $5-1$ & 13 & 3 & 5 & 0 \\
$5-3$ & 14 & 2 & 3 & 0 \\
$5-5$ & 13 & 0 & 8 & 2 \\
$3-1$ & 12 & 1 & 8 & 0 \\
$3-3$ & 20 & 0 & 1 & 0 \\
$3-5$ & 16 & 2 & 3 & 0 \\
\hline
\end{tabular}

sutured into the right nictitating membrane, the surrounding hair removed, and US electrodes applied. Acquisition consisted of six daily sessions of 80 paired CS-US trials for each of four groups of subjects $(n=21)$ differentiated on the basis of amperage of the CR-contingent US. The subjects of Groups 5-5, 5-3, 5-1, and 5-0 received the same 5.0-mA US if no CR occurred and USs of 5.0,3.3,1.6, and $0.0 \mathrm{~mA}$ contingent upon CR occurrence. The intertrial intervals were 60,70 , and $80 \mathrm{sec}$, with a mean of $70 \mathrm{sec}$.

\section{Experiment 2}

Subjects. The subjects were 63 naive male and female albino rabbits, 80-100 days old.

Apparatus and procedure. The apparatus, response specifications, and procedures were the same as those employed in Experiment 1. The number of days training, trials per day, trial distribution, stimulus durations, and intervals were also the same as those employed in Experiment 1. Three groups of subjects $(n=21)$ were differentiated on the basis of the amperage of the CR-contingent US. All subjects were exposed to a standard shock US of $3 \mathrm{~mA}$ when no CR occurred. However, on CR trials, for one group there was a CR-contingent increase in the US to $5 \mathrm{~mA}$ (Group 3-5), for another a CR-contingent decrease to 1 $\mathrm{mA}$ (Group 3-1), and for the third group (a conventional classical conditioning group), the US was not altered (Group 3-3).

\section{RESULTS AND DISCUSSION}

Readers are referred to Coleman (1975) and to Gormezano and Coleman (1973), for group acquisition curves as the focus here is on the two-phase model analysis. The procedures and rationale for obtaining individual-subject parameter estimates are described fully in other recent papers (e.g., Clark \& Prokasy, in press; Prokasy, 1973, 1974; Prokasy, Clark, Williams, \& Spurr, 1975) and will not be detailed here. It should be noted, however, that the estimation procedures do have some biases, and these are described by Clark and Prokasy (in press). Suffice it to say that these biases do not represent a problem for the present theoretical analysis.

Table 1 provides the number of subjects in each treatment condition for whom a particular assumption about the relationships among parameters was sufficient. For most subjects, a single operator (i.e., equal $\theta$ s and equal $\lambda s$ ) during Phase 1 was sufficient. For most of the remaining subjects an assumption of equal $\theta s$ and unequal $\lambda s$ in Phase 2 was sufficient, while few required unequal $\theta \mathrm{s}$. Table 2 includes the means of the parameter estimates for all groups. The table is so designed that the mean value of $K$ is for all subjects, the mean value of $\theta$ with no subscript is the mean for all subjects for whom a single $\theta$ was sufficient, the mean value of $\lambda$ with no subscript is the mean for all subjects for whom a single $\lambda$ was sufficient, etc. The Ns for 
Table 2

Means of Parameter Estimates

\begin{tabular}{crrrrrrr}
\hline & \multicolumn{7}{c}{ Parameters } \\
\cline { 2 - 8 } Group & \multicolumn{1}{c}{$\mathrm{K}$} & $\theta$ & $\lambda$ & $\theta_{1}$ & $\lambda_{1}$ & $\theta_{2}$ & $\lambda_{2}$ \\
\hline $5-0$ & 68.3 & .103 & .841 & & .925 & & .229 \\
$5-1$ & 64.1 & .166 & .976 & .020 & .954 & .114 & .471 \\
$5-3$ & 49.1 & .145 & .977 & .103 & .979 & .369 & .362 \\
$5-5$ & 61.9 & .254 & .974 & & .942 & & .445 \\
$3-1$ & 106.1 & .197 & .970 & .000 & .958 & .182 & .265 \\
$3-3$ & 80.2 & .138 & .976 & & .973 & & .331 \\
$3-5$ & 73.4 & .280 & .981 & .000 & .960 & .223 & .311 \\
\hline
\end{tabular}

each entry can be obtained by combining the appropriate categories from Table 1.

Whether from the associative theory of Rescorla and Wagner or the drive theory of Spence, it would be expected that the duration of Phase 1 would be shorter for high US intensity than for low US intensity. This is because Phase 1 can be interpreted as a below-response-threshold phase during which associative, or habit, strength is incremented until it is sufficient to yield above-baseline response rates. With the higher intensity, a higher limit would be expected from both theories as well as a rate parameter which is at least as large with the higher of the two intensities. This, in turn, means that a response threshold would be reached more rapidly with the higher intensity. As predicted, $\mathrm{K}$ was smaller with the higher (5-mA) US intensity. The mean $\mathrm{K}$ for the 84 subjects receiving an initial US intensity of $5 \mathrm{~mA}$ was significantly less ${ }^{2}$ than that for the 63 who received an initial intensity of $3 \mathrm{~mA}, F(1,45)=9.36$. Within-category differences among $K$ were not reliable.

The effects of US intensity during Phase 2 can be assessed by treating the six groups other than Group 5-0 (i.e., the avoidance group) as part of a 3 by 2 orthogonal design involving 2 levels of US intensity on $\overline{\mathrm{CR}}$ trials ( 3 vs. $5 \mathrm{~mA}$ ) and 3 levels of US intensity on CR trials ( 1 vs. 3 vs. $5 \mathrm{~mA}$ ). The only reliable effect obtained was that $\theta$ increased as a function of CR US intensity, $F(2,102)=3.93$. Neither $\overline{C R}$ US intensity or the interaction of $\mathrm{CR}$ and $\mathrm{CR}$ intensities was reliable, $\mathrm{F}(1,102)=.04$ and .05 , respectively.

The prediction from both the Rescorla-Wagner and the Spence theories was that, given but a single operator during Phase $2, \lambda$ would increase as a function of mean intensity. The failure to obtain a limit effect in itself is not inconsistent with the theories in view of the fact that the mean $\lambda s$ were very high. The analysis made here assumes an ordinal mapping from theoretical strength to observed response measure, an assumption which is reasonable provided that both $P_{0}$ and $\lambda$ are contained within the bounds of .05 and .95 . With higher limits, it is possible that underlying associative, or habit, strength is increasing but cannot be manifest directly in view of the limits which approach unity. Given the high limits and an increasing underlying habit strength beyond what can be mapped ordinally into response probability, the parameter that would be affected would be $\theta$, with increasing $\theta$ being associated with higher US intensity.

While $\theta$ did increase with increases in US intensity, the effect was confined to the US intensity on CR trials. Neither the Spence nor the Rescorla-Wagner theories can account for this result, since both are response-independent theories: the results with $\theta$ should have been the same for both CR and $\overline{C R}$ trials. The current analysis, in separating the effects of US intensity on $\mathrm{CR}$ and $\overline{\mathrm{CR}}$ trials, has no precedent in the literature and hence raises a question about the locus of the effect of US intensity in conditioning. What has been shown is that higher US intensity during Phase 1 reduces the number of trials required to move into Phase 2, an effect primarily occurring on $\overline{C R}$ trials since $P_{0}$ is low, but that during Phase 2 increases the rate of approach to a limit as a function of intensity on CR trials: the locus of effect shifts from $\overline{C R}$ trials during Phase 1 to $C R$ trials during Phase 2. Though not a specific point of study for this paper, the "active-organism" intepretation made by Prokasy et al. (1975) would suggest, first, that higher intensity reduced response search time during Phase 1 and produced a small CR vs. $\overline{C R}$ feedback difference during Phase 2 in spite of the molecular nature of the nictitating membrane response.

For subjects requiring two operators, both theories imply that the higher limit should be associated with the trial category having the higher intensity. This prediction was not realized. A total of 37 subjects across the seven treatments required two limits. For all of these subjects, $\lambda_{1}>\lambda_{2}$ independent of whether the higher intensity were associated with CR or $\overline{C R}$ trials. This result contrasts specifically with what Clark and Prokasy (in press) found with humans: in general, the trend in humans was precisely what was predicted by the two theories, i.e., the larger $\lambda$ associated with the higher intensity whether on CR or $\overline{C R}$ trials. Thus, both the Spence and the RescorlaWagner theories can account for the human, but not the rabbit, data.

Replicating what has been found with humans (Clark \& Prokasy, in press; Prokasy, 1974, 1975), a number of subjects in the classical preparation required two operators during Phase 2. While well within a chance outcome for Group 3-3, the proportion of two-operator subjects in Group 5-5 was reliably greater, $x^{2}(1)=5.1$. Since both theories are response independent, i.e., do not allow for differential effects on $C R$ and $\overline{C R}$ trials, neither theory can account for this result.

A specific comparison meriting note is the contrast between Groups 5-0 and 5-5 or, in effect, between avoidance and classical preparations. Both $\theta$ and $\lambda$ were larger in Group 5-5, F(1.40= 4.88 and $F(1,25)=33.42$, respectively. For those subjects requiring two limits, Group 5-5 had the larger $\lambda_{2}, F(1,13)=8.23$. In addition, both $\lambda$ and $\lambda_{1}$ are well above $P_{0}$, a limit value which should exist for Group 5-0, the avoidance group. None of these outcomes is consistent with theoretical expectation. Omission of the US constitutes an extinction trial for both theories, which means that all subjects should have had a very low limit on CR trials. Not only did most subjects not have a second operator for CR trials, but those who did had a higher limit on CR trials, directly contrary to theoretical expectation. This result contrasts with that obtained with humans, a result more in line with theoretical expectation (Clark \& Prokasy, in press).

In summary, while both the Clark and Prokasy (in press) and the Coleman (1975) data were ordered at a general group level, as expected from both the drive and associative theories, a more detailed analysis with the two-phase model uncovered some severe limitations on the applicability of those theories. For humans, the results were generally, though not entirely, in accord with theoretical expectation in that $\theta s$ and $\lambda s$ were in the order expected. In contrast, parameter estimates obtained from the rabbit protocols showed that neither $\theta$ nor $\lambda$ behaved consistently with theoretical expectation. This permits two conclusions. First, both the Rescorla-Wagner and the Spence theories in their present versions have limited generality. Second, the controlling mechanisms for aversive conditoning in rabbits and humans appear to be different: a theory which accounts for the behavior of one species is unable to account for the behavior of the other.

\section{REFERENCES}

Clark, C. G., \& Prokasy, W. F. Manipulation of responsecontingent unconditioned stimulus intensity in human eyelid conditioning: A two-phase model analysis. Journal of Experimental Psychology: Human Learning and Memory, in press. 
Coleman, S. R. Consequences of response-contingent change in unconditioned stimulus intensity upon the rabbit (Oryctolagus cuniculus) nictitating membrane response. Journal of Comparative and Physiological Psychology, 1975, 88, 591-595.

Coleman, S. R., \& Gormezano, I. Classical conditioning of the rabbit's (Oryctolagus cuniculus) nictitating membrane response under symmetrical CS-US interval shifts. Journal of Comparative and Physiological Psychology, 1971, 77. 447-455.

Gormezano, I., \& Coleman, S. R. The law of effect and CR contingent modification of the UCS. Conditional Reflex, 1973, 8, 41-56.

HeBs, D. O. The distinction between "classical" and "instrumental." Canadian Journal of Psychology, 1956. 10, 165-166.

Perkins, C. C., JR. An analysis of the concept of reinforcement. Psychological Review, 1968, 75, 155-172.

Prokasy, W. F. Developments with the two-phase model applied to human eyelid conditioning. In A. H. Black and W. F. Prokasy (Eds.), Classical conditioning II. New York: Appleton-Century-Crofts, 1972.

Prokasy, W. F. A two-phase model account of aversive classical conditioning performance in humans and rabbits. Learning and Motivation, 1973, 4, 247-258.

Prokasy, W. F. Discriminated avoidance vs. classical conditioning: A two-phase model analysis. Animal Learning \& Behavior, 1974, 2, 257-261.

Prokasy, W. F., Clark, C. G., Williams, W. C., \& Spurr, C. W. Conditioned response-contingent delays of the unconditioned stimulus in human aversive conditioning. Journal of Experimental Psychology: Human Learning and Memory, 1975, 1, 513-520.

Prokasy, W. F.. \& Harsany. M. A. Two-phase model for human classical conditioning. Journal of Experimental Psychology' 1968, 78, 359-368.

Rescorla, R. A., \& Wagner, A. R. A theory of Pavlovian conditioning: Variations in the effectiveness of reinforcement and nonreinforcement. In A. H. Black and W. F. Prokasy (Eds.), Classical conditioning II. New York: AppletonCentury-Crofts, 1972.

Schlosberg, $H$. The relationship between success and the laws of conditioning. Psychological Review, 1937, 44. 379-394.

Spence, K. W. Behavior theory and conditioning. New Haven: Yale University Press. 1956.

SPENCE, K. W. The roles of reinforcement and nonreinforcement in simple learning. In $K$. W. Spence (Ed.). Behavior theory and learning. Englewood Cliffs, NJ: Prentice-Hall, 1960.

\section{NOTES}

1. These data were supplied by Professor I. Gormezano.

2. The .05 rejection region was adopted for all statistical comparisons.

(Received for publication December 22, 1975.) 